\title{
Experimental research on the rotating detonation in gaseous fuels-oxygen mixtures
}

\author{
J. Kindracki · P. Wolański · Z. Gut
}

Received: 31 October 2009 / Revised: 27 October 2010 / Accepted: 30 December 2010 / Published online: 29 January 2011

(C) The Author(s) 2011. This article is published with open access at Springerlink.com

\begin{abstract}
An experimental study on rotating detonation is presented in this paper. The study was focused on the possibility of using rotating detonation in a rocket engine. The research was divided into two parts: the first part was devoted to obtaining the initiation of rotating detonation in fueloxygen mixture; the second was aimed at determination of the range of propagation stability as a function of chamber pressure, composition, and geometry. Additionally, thrust and specific impulse were determined in the latter stage. In the paper, only rich mixture is described, because using such a composition in rocket combustion chambers maximizes the specific impulse and thrust. In the experiments, two kinds of geometry were examined: cylindrical and cylindricalconic, the latter can be simulated by a simple aerospike nozzle. Methane, ethane, and propane were used as fuel. The pressure-time courses in the manifolds and in the chamber are presented. The thrust-time profile and detonation velocity calculated from measured pressure peaks are shown. To confirm the performance of a rocket engine with rotating detonation as a high energy gas generator, a model of a simple engine was designed, built, and tested. In the tests, the model of the engine was connected to the dump tank. This solution enables different environmental conditions from a range of flight from $16 \mathrm{~km}$ altitude to sea level to be simulated. The obtained specific impulse for pressure in the chamber of max.
\end{abstract}

Communicated by S. Dorofeev and L. Bauwens.

This paper is based on work that was presented at the 22nd International Colloquium on the Dynamics of Explosions and Reactive Systems, Minsk, Belarus, July 27-31, 2009.

J. Kindracki ( $\varangle)$ · P. Wolański · Z. Gut

Institute of Heat Engineering, Warsaw University of Technology,

Warsaw, Poland

e-mail: jkind@itc.pw.edu.pl

URL: http://www.itc.pw.edu.pl
1.2 bar and a small nozzle expansion ratio of about 3.5 was close to $1,500 \mathrm{~m} / \mathrm{s}$.

Keywords Rotating detonation $\cdot$ RDE engine

\section{Introduction}

Combustion scientists' interest has recently focused on development of the Rotating Detonation Engine (RDE), known also as the Continuous Detonation Wave Engine. This is because it simultaneously offers significant improvements in thermal efficiency and simplification of the design. In the early 1960s, Voitsekhovskii, Metrofanov, and Topchian performed experiments on continuously rotating detonation [1,2]. In 2004, Tobita (Mitsubishi Heavy Industry), Fujiwara, and Wolanski applied for a Japanese patent on the RDE, and a similar application was repeated for a US Patent in 2005 [3]. Recently, many experimental researches in this field have been conducted in various laboratories [4-8]. The principle of the RDE is based on the creation of continuously propagating detonation in a disk-like combustion chamber (a toroidal or ring-like shape). The fresh mixture (fuel-air or fuel-oxygen) is supplied from one side and combustion products expand from the other side of the chamber (see Fig. 1).

The use of detonation as a combustion process is motivated by the expectation of improving the performance of jet propulsion. Cycles based on detonation are more thermodynamically efficient. In detonation, chemical energy release occurs in a very short time and in a small space in comparison to the deflagration mode. All detonation engines can be divided into three groups. The first one is called the Standing Detonation Engine [9], where injection of the mixture is continuous, which ensures a constant thrust value. The injection 
Fig. 1 Schematic diagram of the Rotating Detonation Chamber and flow pattern

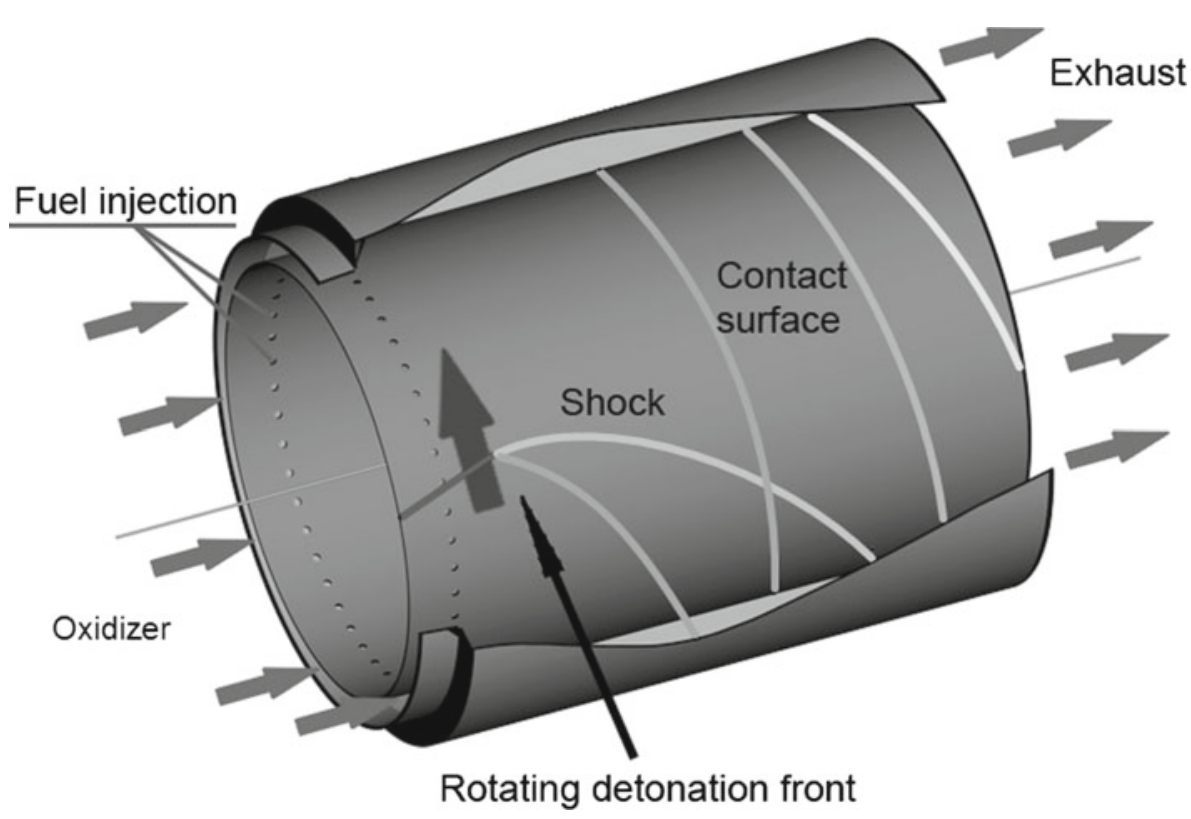

velocity of the fresh mixture is strictly limited, because the detonation wave cannot move along the engine. The equilibrium between the injection velocity and the propagation velocity can be easily disturbed by a small change in the mixture composition or by another factor. The engine can operate only in a particular range of velocities.

The second group of detonation engines is called the Pulsed Detonation Engine (PDE) and its design is very simple $[9,10]$. It can operate in a wide range of conditions (e.g. for a flight Mach number in the range 0-5), but its thrust changes during the operation cycles, periodically increasing and decreasing. Additionally, the system is complicated since it needs purging and refilling. Another problem with the engine is an initiation system, because in each cycle it needs ignition from some source and then fast transition from deflagration to detonation (DDT). To reduce DDT time, the PDE engine should use a stoichiometric mixture that generates a high temperature and high $\mathrm{NO}_{x}$ emission.

The third group of detonation engines is called the RDE (also known as the Continuous Detonation Wave Engine). The RDE engine can operate for any flight velocity, generating a stable thrust value, because the engine has a very high frequency of repetition (thousands of cycles per second depending only on the mixture and geometry of the engine). It has an essential advantage: initiation of the process takes place only once and it then propagates continuously and can work with a lean and rich mixture, which reduces the maximum temperature and $\mathrm{NO}_{x}$ production. The length of the combustion chamber can be shortened, because the combustion zone is shorter than that in the deflagration mode, and does not need a mixing with secondary air flow. The shorter the chamber, the lower the mass of the engine can be.

\section{The research stand}

\subsection{The "small" chamber}

The research stand consisted of a few main parts: detonation chamber (1), damp tank $(3)$, fuel $(8,10)$ and oxygen $(7,9)$ feeding systems, and measurement and initiation systems (2). The chamber was equipped with a few pressure transducers. Two of them were placed in the manifolds and the others were installed in the chamber. The detonation chamber was connected to the dump tank (whose volume was about $0.63 \mathrm{~m}^{3}$ ). The schematic diagram and a view of the research stand are shown in Fig. 2. The configuration of the research facility for thrust measurement experiments is presented in Fig. 3.

This configuration allowed conditions similar to a nearvacuum regime to be simulated. The detonation chamber was constructed by using easily changeable modular elements (which enable the internal diameter of the chamber $D_{\mathrm{ch}}=$ $38 \mathrm{~mm}$ and length of the channel $L_{\mathrm{ch}}=23-50 \mathrm{~mm}$ or shape of the inner wall of the chamber to be changed). Fuel and oxygen were injected into the chamber by two kinds of injectors: fuel by a number of small orifices (with diameters in the range $0.7-1 \mathrm{~mm}$ ) and oxygen by a slit with changeable width $(\delta=0.5-1 \mathrm{~mm})$. The whole process was controlled by a specially designed control unit which was connected with the computer and the measurement system.

Figure 4a shows the scheme of the detonation chamber with the directions of flow of fuel, oxygen, and exhaust gases. The geometry of the oxygen slit and fuel holes was designed to obtain and keep the sonic condition of flow for both components. Obviously, the manifold-chamber pressure ratio must be kept at the selected level for the whole experiment. This 
(a)

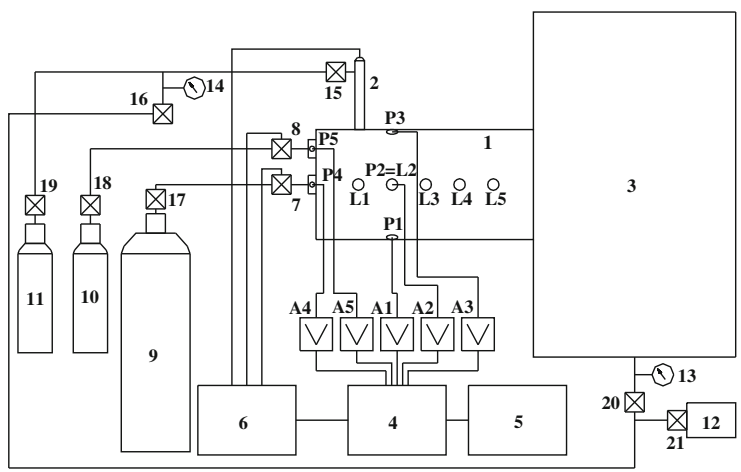

Fig. 2 The research stand: a schematic diagram: $P 1-P 3$ pressure transducers placed in one plane inside chamber, $L 1-L 5$ pressure transducers placed in one line inside the chamber, $P 4, P 5$ pressure transducers for manifolds: fuel and oxygen, $A 1-A 5$ amplifiers, 1 detonation chamber, (b)

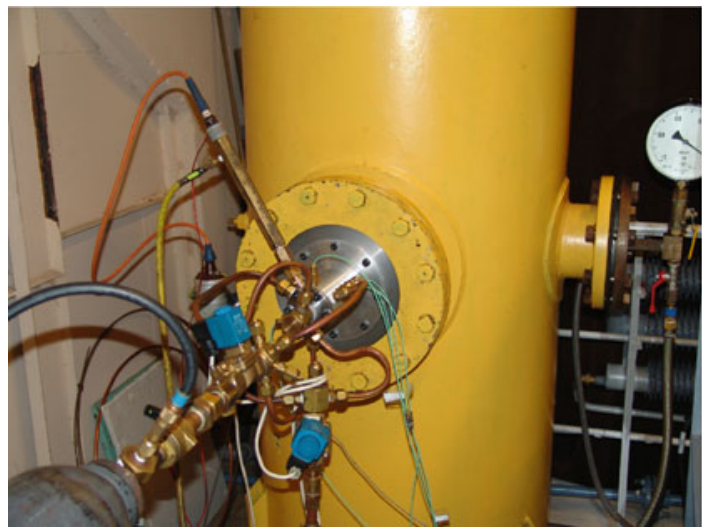

2 initiation tube, 3 dump tank, 4 acquisition card, 5 computer, 6 control system, 7,8 electromagnetic valves, 9 tank with the oxygen, 10 tank with the fuel, 11 tank with initiation mixture, 12 vacuum pump, 13,14 manometers, $15-21$ valves; $\mathbf{b}$ view of the stand (a)

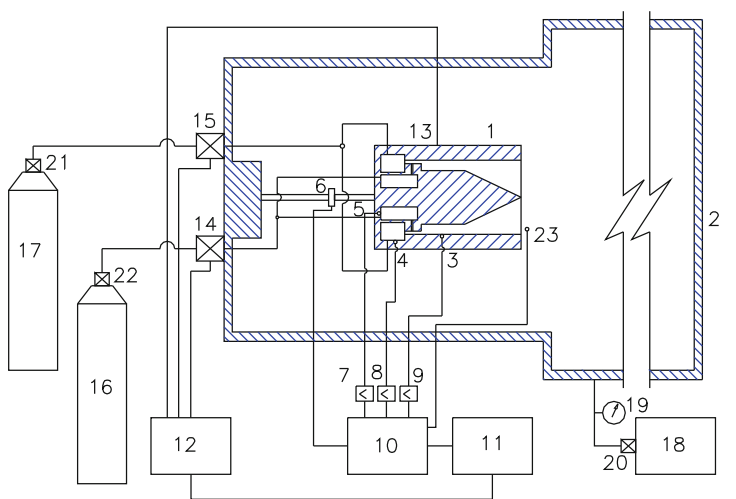

Fig. 3 The research stand in thrust measurements configuration: 1 detonation chamber (model of rocket engine), 2 dump tank, 3 chamber pressure transducer, 4 oxygen manifold pressure transducer, 5 fuel manifold pressure transducer, 6 thrust sensor, 7-9 amplifiers, 10 acquisition card, (b)

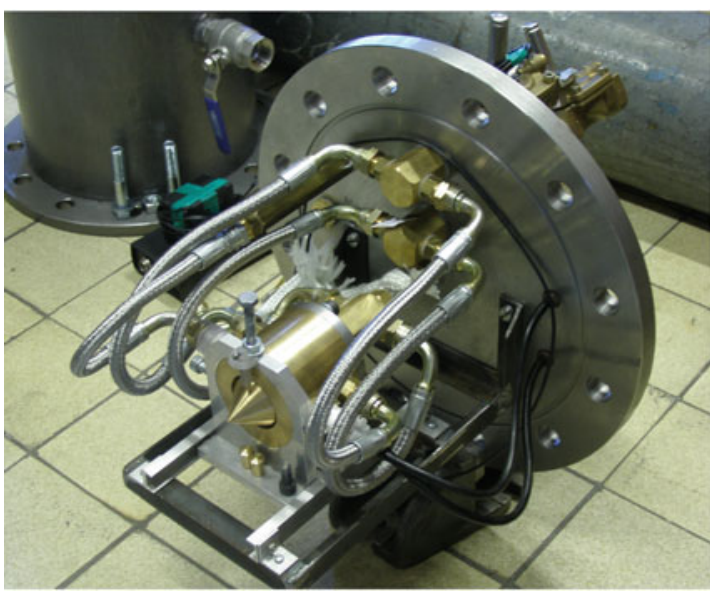

11 computer, 12 control unit, 13 ignitron system, 14, 15 electromagnetic valves, 16 tank with fuel, 17 tank with oxygen, 18 vacuum pump, 19 manometer, $20-22$ valves, 23 thermocouple (a)

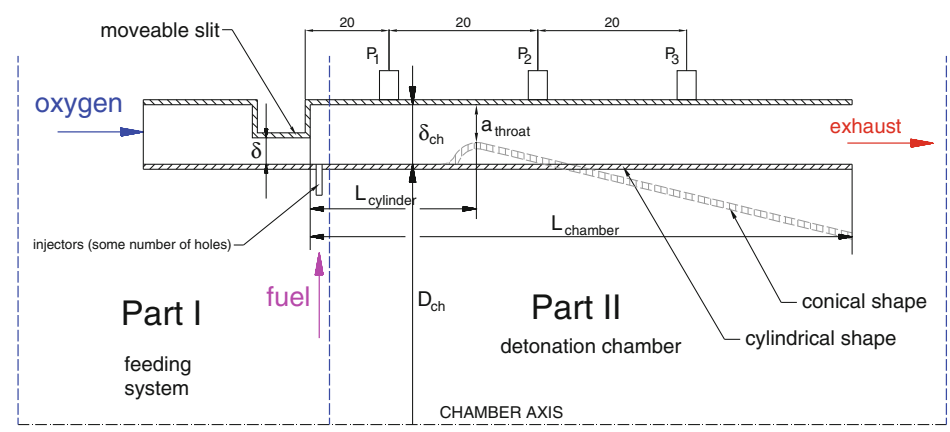

(b)

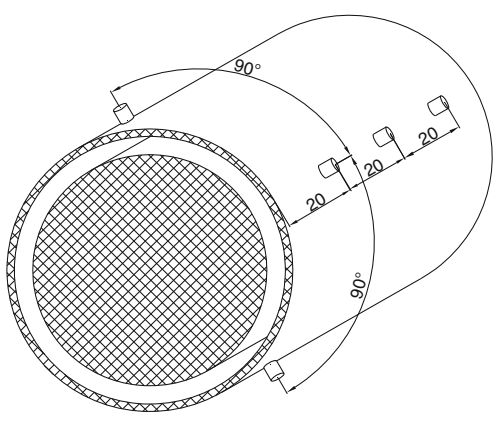

Fig. 4 Detonation chamber: a scheme of cross-section: $D_{\mathrm{ch}}, L_{\mathrm{chamber}}$, internal diameter/length of the chamber; $L_{\mathrm{cylinder}}$, length of cylindrical part; $a_{\text {throat }}$, dimension of the throat; $\delta$, width of the oxygen slit; $\delta_{\mathrm{ch}}$, width of the chamber channel; $P_{1}, P_{2}, P_{3}$, locations of line gauge pressure; $\mathbf{b}$ locations of the chamber pressure transducers 
Fig. 5 The research stand in thrust measurements configuration for the large size, $150 \mathrm{~mm}$ : a the stand with measurement equipment; $\mathbf{b}$ the model of the engine with aerospike nozzle (a)

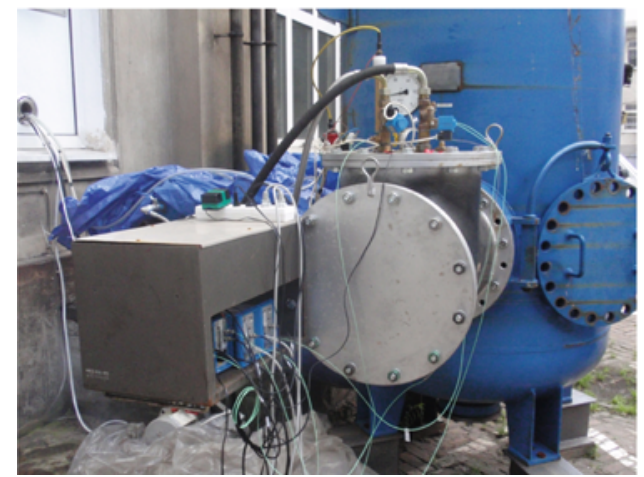

(b)

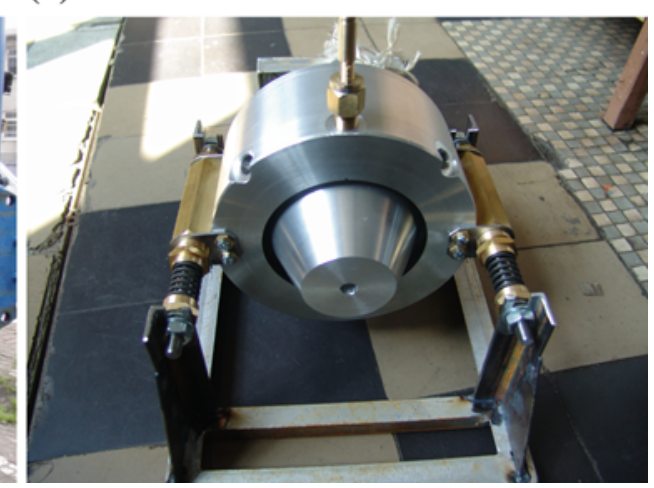

approach allowed maximization of the flow rate and degree of mixing rate in the short distance. To control both flows, electromagnetic valves (Fig. 2) with a fast response time (only 20-25 ms from the start signal to full flow) were used. The ignition system was connected with a control valves by a control unit and was started when the flow of the composition of the mixture achieved maximum value. Thanks to this and a selection of the proper method of initiation, the probability of ignition of the mixture in the chamber was close to $100 \%$.

In the experiments described, two methods of initiation were tested. The first used a commercial spark plug placed into the channel of the chamber and initiated the examined mixture directly. Energy released in one discharge was about $1.6 \mathrm{~J}$ and was not enough to initiate the mixture in every test (the repeatability of this initiation method for the methaneoxygen mixture was about $40 \%$ ). The second one used an additional small tube filled with a sensitive, acetylene-oxygen mixture and started by an ordinary spark plug. The initiation mixture was separated from the chamber channel by a thin plastic diaphragm. After initiation, the hot detonation gases burst the diaphragm and formed a shock wave. The initiation tube can be connected with the main chamber in any position: tangential, perpendicular, and so on. This method is known as an indirect method using a strong shock wave (repeatability was more than 95\%).

As already mentioned, several pressure transducers in the research facility were used. Two of them were installed in the fuel and oxygen manifold; the others were placed in the chamber at the location shown in Fig. 4b. For the desired experiment, transducers were organized in two kinds of orders: in one plane or in one line along the axis, but most of the experiments were carried out with one chamber sensor. For a specific case, e.g., thrust measurements, the operation time was longer (up to $0.8 \mathrm{~s}$ ), and the pressure transducers were used with the application of a small layer of silicon grease on the front surface. This solution protected the sensor from intensive heating by hot detonation products.
The duration of a typical experiment was about $150 \mathrm{~ms}$, but in some cases when the thrust was measured, the experiment time was extended to $0.8 \mathrm{~s}$. Generally, the duration of the tests depended on the initial pressure in the dump tank as well as on other test parameters. For the cases with thrust measurement, the detonation chamber with all essential systems was placed inside the dump tank.

\subsection{The "big" chamber}

The test stand configuration is almost the same as that in the "small" chamber. The main difference is the larger outer and inner chamber diameter of 150 and $140 \mathrm{~mm}$, respectively, and larger dump tank of $3.6 \mathrm{~m}^{3}$. The engine with supply lines was put into a special extension tube (see Fig. 5a) and fixed on a special ramp (see Fig. 5b). The gas storage system has $0.16 \mathrm{~m}^{3}$ capacity for each component of the mixture. For thrust measurement, a $2 \mathrm{kN}$ range force transducer was used. The stand allowed various altitude conditions from sea level up to $16 \mathrm{~km}$ to be simulated.

\section{Experimental results}

The first goal of the research was confirmation of the initiation of rotating detonation in fuel-oxygen mixture. The aim was achieved in the facility described above with methane as a fuel. Figure 6 shows one of the first successful results for cylindrical-conic geometry (length of the cylindrical part of the channel $=30 \mathrm{~mm}$, next to a conic section with an angle of $77^{\circ}$ ). Part "a" of the figure shows the whole process; part " $b$ " shows the moment of initiation in the main chamber by a strong shock wave. Typically for this moment, there is a high pressure rise connected with rapidly decreasing pressure behind the shock wave and next some delay time before the start of the rotation detonation. The delay time depended on the energy released by the shock wave (initial pressure inside the initiation tube), which was demonstrated by the author 
Fig. 6 Pressure-time history for rich methane-oxygen mixture, initial pressure 0.8 bar: a whole experiment, $\mathbf{b}$ initial shock wave, $\mathbf{c}, \mathbf{d}$ stability propagation at different times
Fig. 7 Pressure-time history for rich methane-oxygen $1 \mathrm{bar}$, for different distances of pressure transducers from the injection plane (cylindrical geometry): a $20 \mathrm{~mm}$, b $40 \mathrm{~mm}$, and $\mathbf{c} 60 \mathrm{~mm}$

Fig. 8 Pressure-time history for rich methane-oxygen mixture, initial pressure 0.8 bar. Distance of pressure transducers from injection plane (cylindrical-conic geometry): a $20 \mathrm{~mm}, \mathbf{b} 40 \mathrm{~mm}$, and c $60 \mathrm{~mm}$ mixture for an initial pressure of (b)

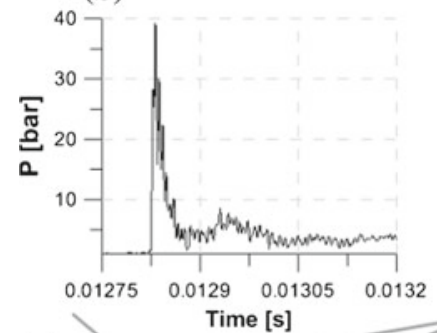

(c)

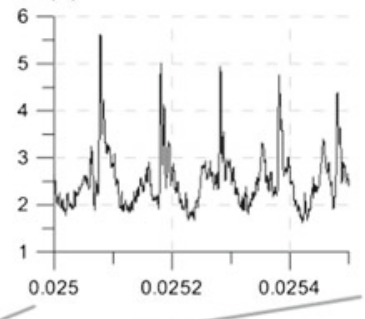

(d)

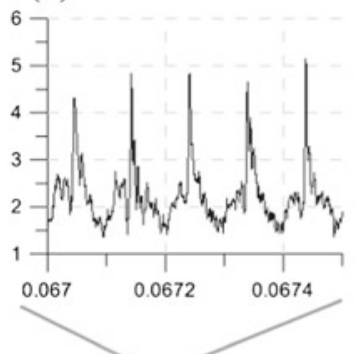

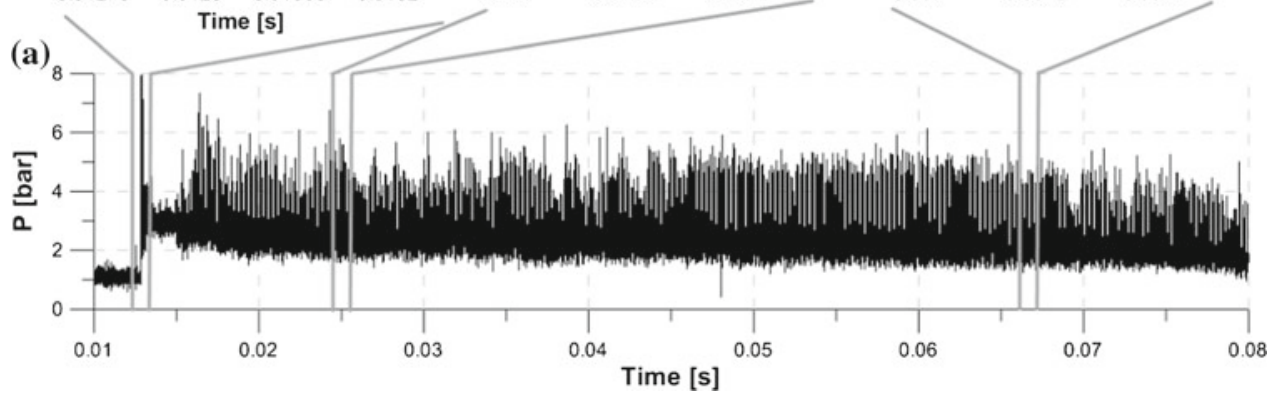

(a)

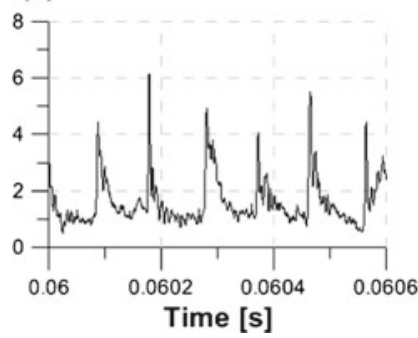

(a)

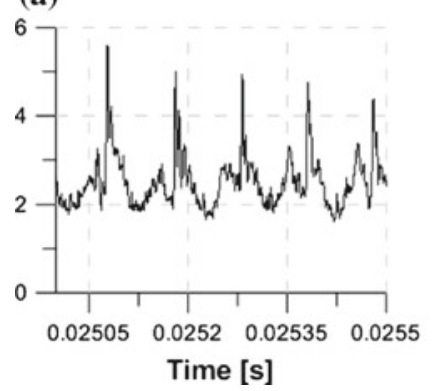

(b)

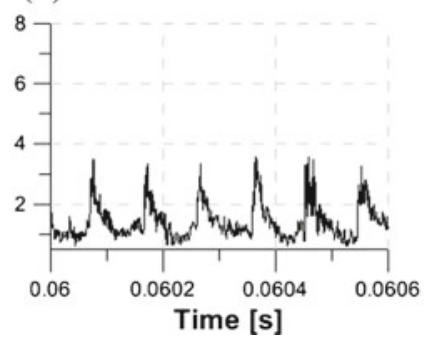

(b)

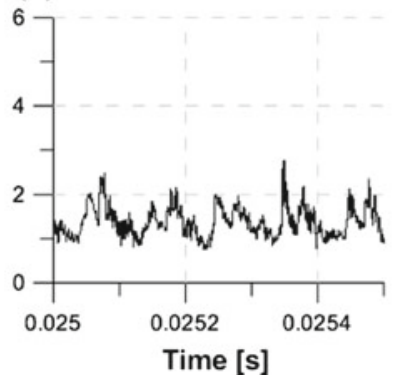

(c)

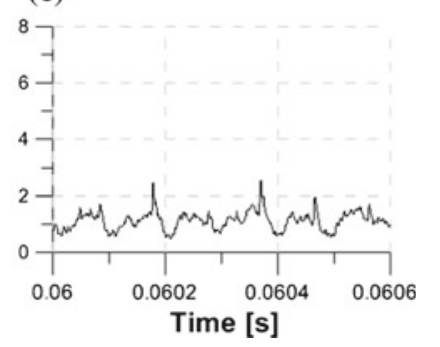

(c)

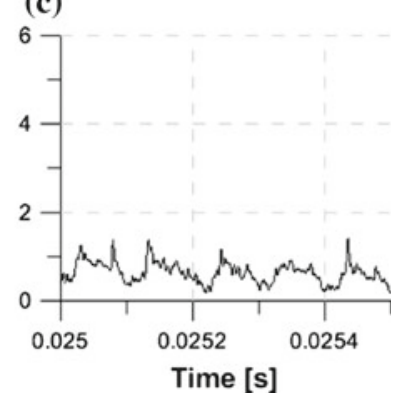

in [11]. Parts "c" and "d" of Fig. 6 show fully developed propagation of rotating detonation.

The second goal of the presented research was to determine the location (along the chamber) of the detonation wave, namely, to determine the shortest length of the chamber channel which supports stable propagation of rotation detonation. Three transducers placed in a line along the chamber axis (see Fig. 4) were used to answer this question. Figure 7 shows the pressure-time history for cylindrical geometry (the length of the channel was $50 \mathrm{~mm}$ ); the initial pressure was equal to 1 bar. It can be seen in Fig. 7 that the detonation wave propagated near the first sensor. A similar result can be observed for cylindrical-conic geometry (Fig. 8). The mean pressure inside the chamber, indicated by the first gauge for the cylindrical case, was equal to 1.25 bar and decreased as it approached the exit to 1.2 and $1.1 \mathrm{bar}$, respectively. The

pressure decrease was caused by heat exchange and flow friction losses. Also in Fig. 8, a significant decrease in the mean pressure for cylindrical-conic geometry can be observed and is explained by the existence of a divergent nozzle. The geometric parameters of the case were: $D_{\text {chamber }}=38 \mathrm{~mm}$, $\delta_{\mathrm{ch}}=4 \mathrm{~mm}, a_{\text {throat }}=1.9 \mathrm{~mm}, L_{\text {cylinder }}=30 \mathrm{~mm}$, and a divergent section that was conic with $77^{\circ}$. By comparing the two cases described above, it can be found that for comparable initial thermodynamic conditions the second geometry gives higher values of mean pressure. In other words, the geometry has greater potential energy, which can be changed to kinetic energy inside the nozzle.

The third goal was to examine different fuel-oxygen mixtures. Figures 10-13 show typical pressure records of the rotating detonation propagation in the "small" chamber for different fuels: methane, ethane, and propane, in a small 
Fig. 9 Methods of calculation of detonation velocity from experimental data

Fig. 10 Pressure-time course (upper part) recorded on the outer chamber wall for rich methane-oxygen mixture; the initial pressure was 0.8 bar (small chamber, cylindrical shape of the wall). Detonation velocity-time course (lower part) evaluated from recorded peak pressures

Fig. 11 Pressure-time course (upper part) recorded on the outer chamber wall for rich ethane-oxygen mixture; the initial pressure was 0.5 bar (small chamber, cylindrical shape of the wall). Detonation velocity-time course (lower part) evaluated from recorded peak pressures
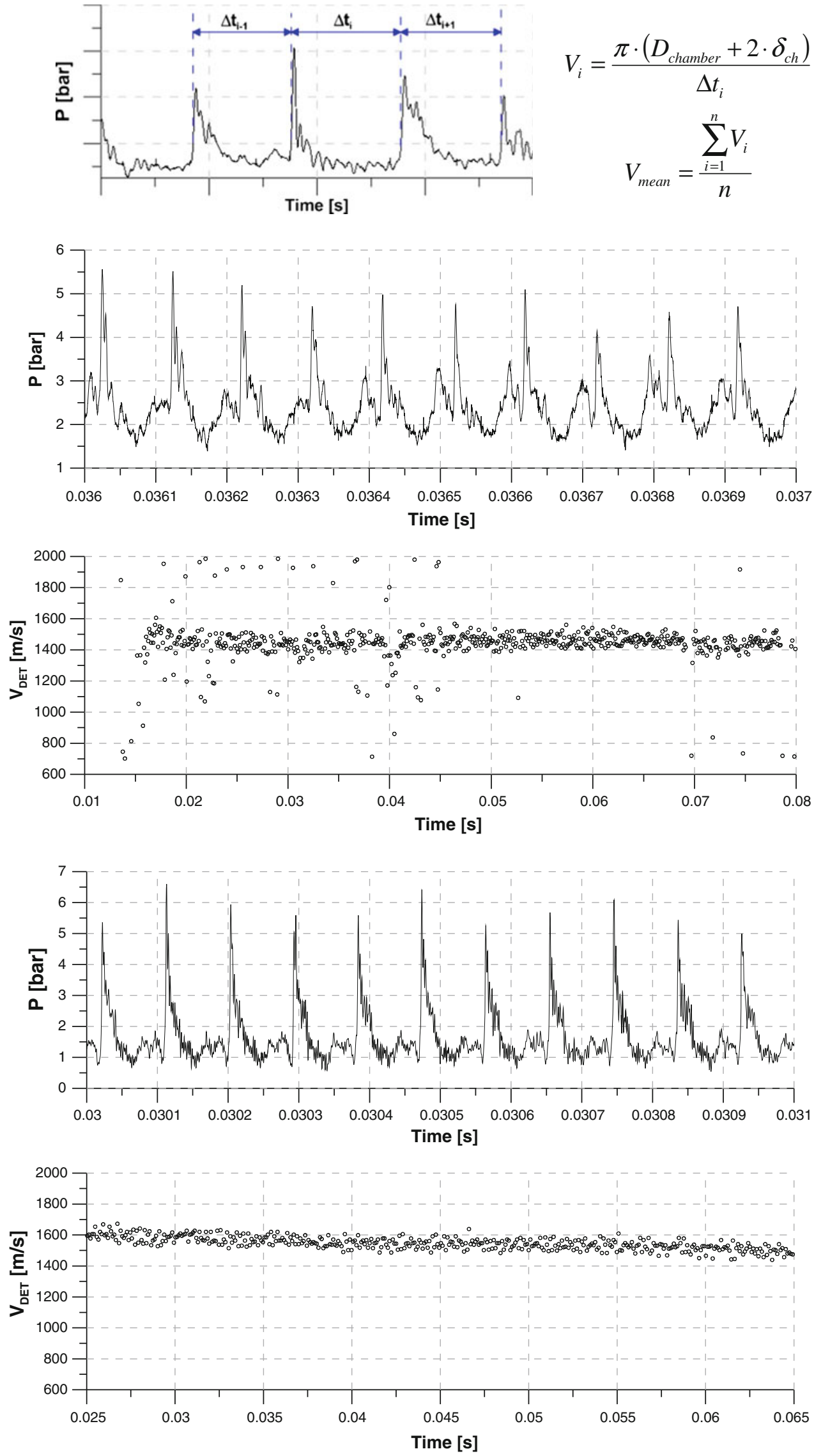
Fig. 12 Pressure-time course (upper part) recorded on the outer chamber wall for rich propane-oxygen mixture; the initial pressure was 0.2 bar (small chamber, cylindrical shape of the wall). Detonation velocity-time course (lower part) evaluated from recorded peak pressures
Fig. 13 Pressure-time course (upper part) recorded on the outer chamber wall for rich propane-oxygen mixture; the initial pressure was 1 bar (big chamber, cylindrical shape of the wall). Detonation velocity-time course (lower part) evaluated from recorded peak
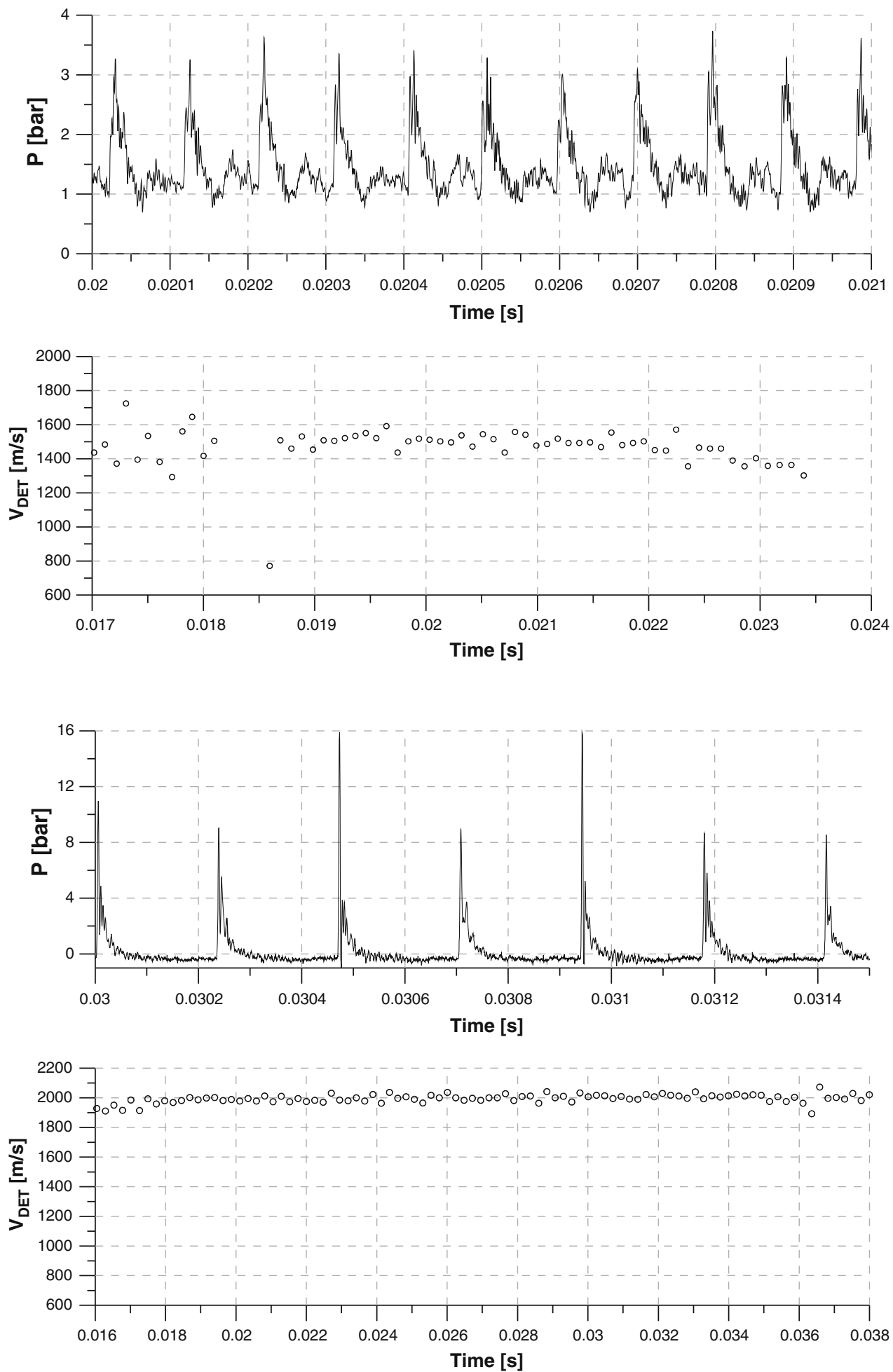

chamber. The lower parts of the graphs show a circumferential component of the detonation velocity calculated from pressure peaks. The method of calculation of the detonation velocity is shown in Fig. 9. Since the calculations were carried out for all pressure peaks, different values of instant detonation velocity $\left(V_{i}\right)$ were obtained. For that reason the detonation velocity was calculated as the mean value of instantaneous velocities ( $\left.V_{\text {mean }}\right)$ (Fig. 14):

In all presented cases, the stability of the propagation is very good. The mean velocity for those fuels in the "small" chamber is in the range $1,400-1,600 \mathrm{~m} / \mathrm{s}$. The small decrease in the velocity (see Fig. 11) is a result of changing the mixture 


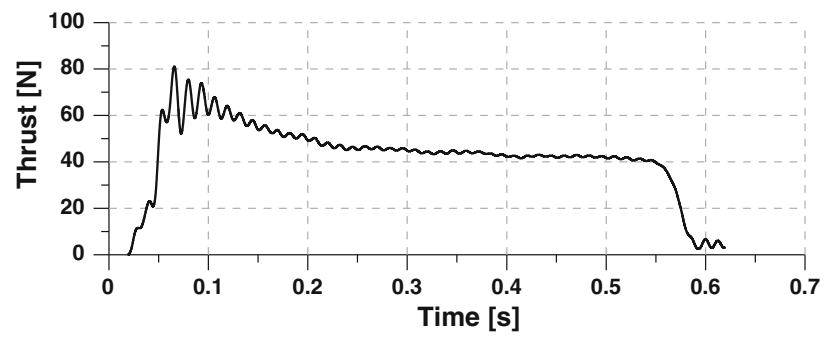

Fig. 14 Thrust-time profile for methane-oxygen mixture; the initial pressure was 0.1 bar (small chamber with aerospike nozzle)

compositions. Both tanks have the same capacity, but the flow rates of the fuel and air are different. Figure 10 shows the pressure and velocity during the propagation in the "big" chamber. The observed velocity is higher by about $400 \mathrm{~m} / \mathrm{s}$ compared to the "small" chamber. This phenomenon was probably caused by the larger radius of curvature in the chamber. Also, the different expansion of the exhaust gases is caused by the change in the abovementioned velocity.

The magnitude and repeatability of pressure peaks are not perfect. The reason for this phenomenon is a locally incomplete mixing, and the degree of the mixing is different for each cycle. On the other hand, the local composition of the mixture can also be changed and affected by the velocity of the detonation wave. The fluxes of detonation velocity forced variations in the duration of the full cycle. Additionally, the wave front also pulsates along the axis of the chamber and the detonation wave does not always pass perfectly above the gauge, which is fixed in one place in a given experiment. Furthermore, in numerical calculations made by Kobiera et al. [12] or Hishida et al. [13], the pressure peaks of various amplitudes were also reported. The detonation phenomenon is itself an unstable process that is very sensitive to small disturbances of the initial parameters.

After completing the first part of the research (examination of the "small" chamber), the larger chamber was designed and constructed with a modified supplying system and with a new nozzle. Among the fuel-oxygen mixtures tested, the detonation was most stable when using methane and oxygen, and for this reason the research using the large chamber was limited to this mixture only. Additionally, in rocket technology, methane will probably be the most economic fuel; it and oxygen have almost the same temperature in the liquid state, which simplifies the whole feeding system.

As mentioned before, in the stand, a $3.6 \mathrm{~m}^{3}$ dump tank was used with the model of the engine installed inside. Such a solution allowed simulation of the engine at higher altitudes. Most of the experiments were carried out for dump tank pressures in the range $0.2-0.5$ bar. The mean flow rates of the methane and oxygen were 0.06 and $0.15 \mathrm{~kg} / \mathrm{s}$, respectively, giving an equivalence ratio about 1.65 . Such flow rates enable a mean thrust value of about $250-300 \mathrm{~N}$ to be achieved. The thrust as a function of time is shown in Fig. 15. The visible decrease of the thrust at the end of measurement was caused by exhaust gases which filled the dump tank and increased back pressure (the green curve at the bottom part of Fig. 15). The thrust observed before the ignition (between 50 and $110 \mathrm{~ms}$ ) is a result of the outflow of cold gases and is about $25 \mathrm{~N}$. During the initial time, the pressure in the dump tank increased very quickly, and after about $0.11 \mathrm{~s}$, the increase became moderated by the process of water vapour condensing on the cold dump tank wall. The bottom part of Fig. 15 shows the feeding pressure in the manifolds' methane (black curve) and oxygen (blue curve). The pressures in the manifolds were approximately constant at the level of 7 bar during the whole experiment.

\section{Calculation of specific impulse}

For calculation of the performance of the model engine with rotating detonation, the freeware software CEA [12] was used. The program calculates a specific impulse as a function of the mixture composition, the pressure in the combustion chamber, and the nozzle expansion ratio. The calculation of rocket performance is based on several assumptions. The basic ones are: one-dimensional form of the flow equations; ideal-gas law; homogeneous mixing; complete and adiabatic combustion; isentropic expansion in the nozzle; and zero velocity at the chamber inlet. The results of the calculations show the maximum possible value of the specific impulse because the program does not take into account any losses. It is possible to make the calculation in two modes: equilibrium and frozen. Equilibrium mode means that the composition of exhaust gases and the thermodynamic parameters are calculated in each cross-section of the engine with chemical equilibrium by the method of minimization of free energy. The second one uses calculation of the composition of combustion gases in the combustion chamber and freezes it for all of the next cross-section. More details about these methods can be found in $[14,15]$. Table 1 shows the results of the specific impulse calculation with input data that are the same as experimental values: chamber pressure, flow rate, and back pressure for three time snapshots. Figure 16 shows a comparison of the specific impulse for the CEA calculation (blue circles) and the experimental value (black points, and curve-mean value). The results achieved in the experiment are close to theoretical estimations. The relatively low specific impulse in both theoretical calculations and experiments is a result of low chamber pressure and a small nozzle expansion ratio. 
Fig. 15 Results of pressure in feeding lines (black and blue curves), pressure in the dump tank (green curve), and thrust (red curve) as a time function for chamber pressure $\sim 1$ bar and initial pressure in the tank of 0.1 bar ( $16 \mathrm{~km}$ altitude $)$
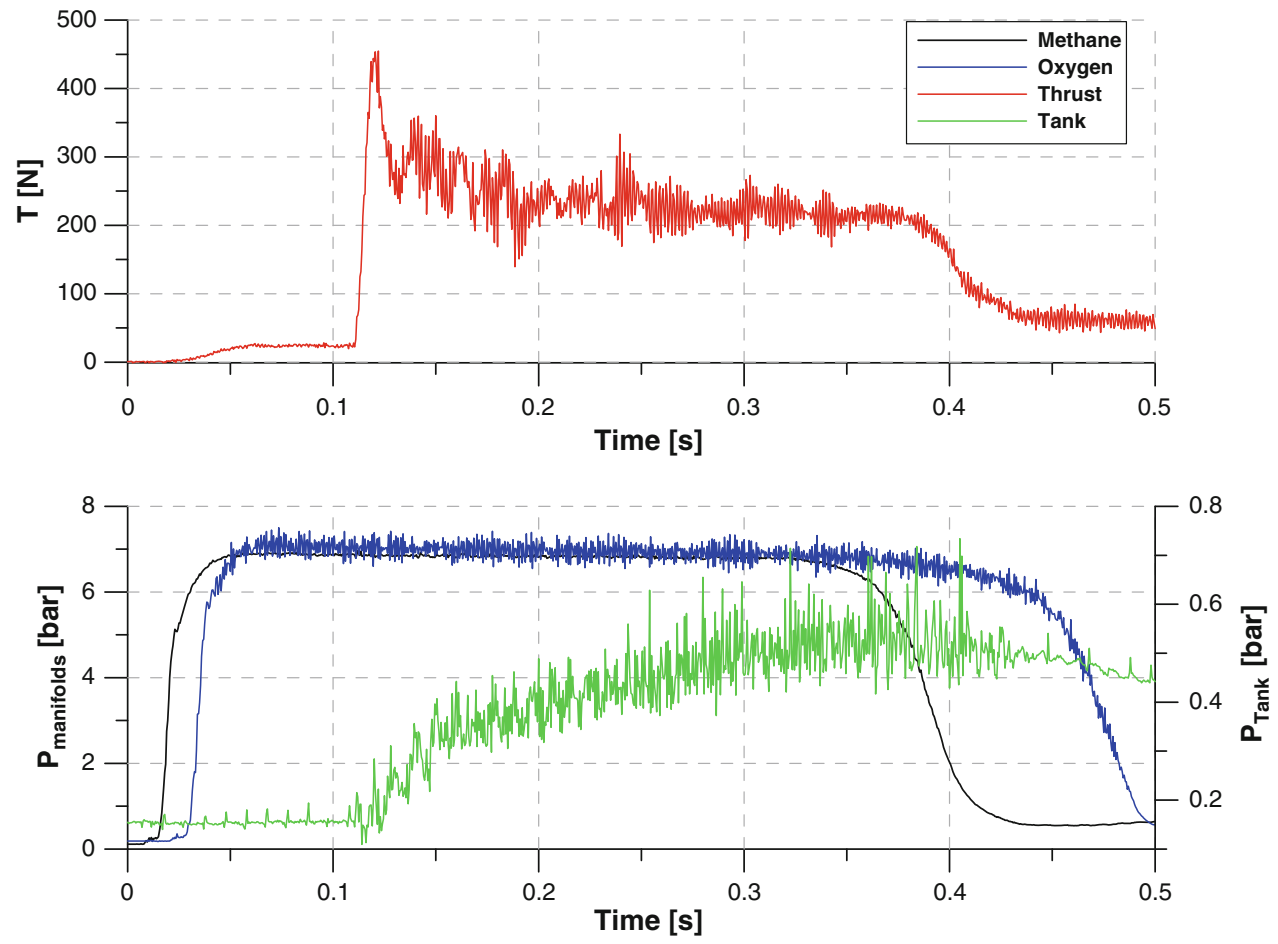

Table 1 Results of theoretical calculation of specific impulse

\begin{tabular}{|c|c|c|c|c|c|c|c|c|}
\hline & \multirow[t]{2}{*}{$T(\mathrm{~s})$} & \multirow[t]{2}{*}{$\phi$} & \multirow[t]{2}{*}{$p_{\text {ch }}($ bar $)$} & \multirow[t]{2}{*}{$p_{\text {tank }}(\mathrm{bar})$} & \multirow{2}{*}{$\begin{array}{l}\text { Mass flow } \\
\text { rate }(\mathrm{kg} / \mathrm{s})\end{array}$} & \multirow[t]{2}{*}{$p_{\mathrm{ch}} / p_{\text {tank }}$} & \multicolumn{2}{|c|}{ Specific impulse $(\mathrm{m} / \mathrm{s})$} \\
\hline & & & & & & & Equilibrium state & Frozen state \\
\hline 1 & 0.14 & 1.67 & 0.97 & 0.3 & 0.212 & 3.23 & 1,816 & 1,774 \\
\hline 2 & 0.20 & 1.68 & 0.97 & 0.4 & 0.217 & 2.42 & 1,592 & 1,564 \\
\hline 3 & 0.30 & 1.69 & 0.97 & 0.5 & 0.220 & 1.94 & 1,386 & 1,368 \\
\hline
\end{tabular}

Fig. 16 Comparison of theoretical calculation with CEA and experimental measurements. The blue circles are the result of calculation for conditions during an experiment at exactly the same time

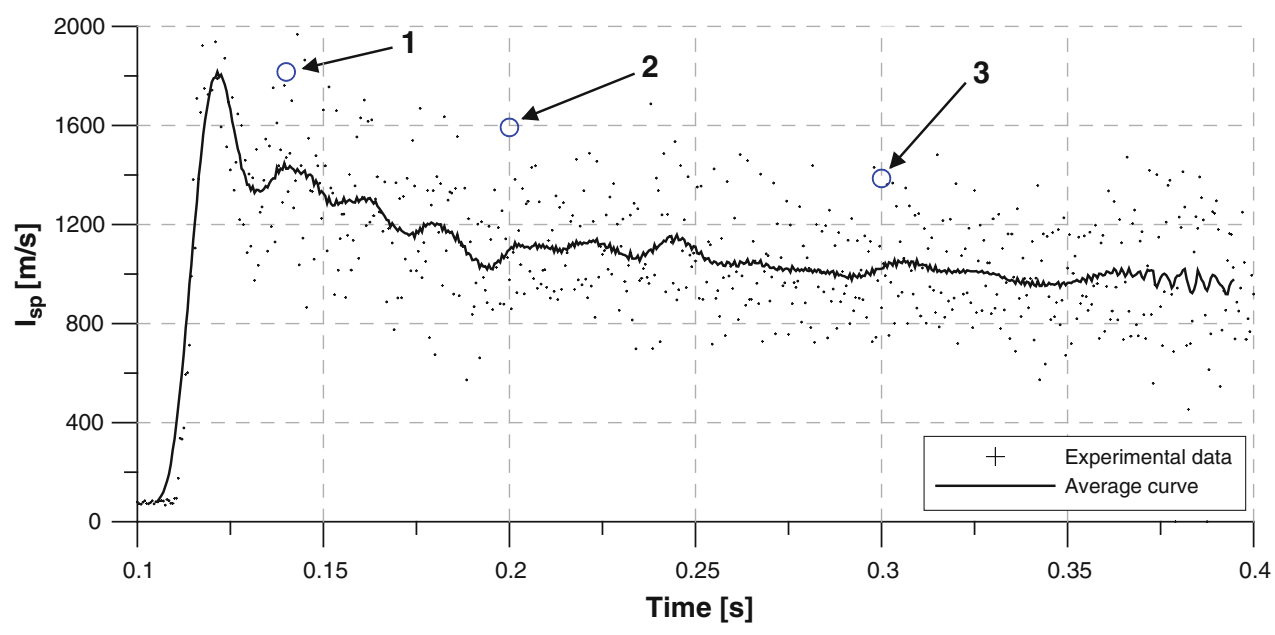

\section{Conclusions}

Analysis of the presented research allowed several conclusions on rotating detonation and it application to the rocket engine to be drawn, which are collected in a few main points:
- It was experimentally shown that rotating detonation can be established for gaseous mixtures of methane, ethane, and propane with oxygen.

- Experimental comparison of two different geometries showed their ability to support the rotating detonation. 
- The achieved performances, thrust and specific impulse, are relatively low, but they are very promising for the application of such processes to rocket propulsion. Using a higher chamber pressure should improve the propulsion performance. Additionally, the aerospike nozzle and the rotating detonation during the combustion process allow self-adaptation of the outflow from the engine during atmospheric flight.

- More experimental, numerical, and theoretical research is necessary before engines with detonation as the combustion process can become a reality, but today we are one step closer to fulfillment of that dream.

- On the other hand, the results of the experiments create a question: how does the mixing process influence the propagation of the rotation detonation and the performance of the particular engine. Which is better in this application: the more or the less complete mixing process?

- The next step should be both theoretical and experimental analysis of flow-wall heat exchange.

Acknowledgments The research was supported by the Polish Ministry of Science and Higher Education, Project No. 4T12D02429.

Open Access This article is distributed under the terms of the Creative Commons Attribution Noncommercial License which permits any noncommercial use, distribution, and reproduction in any medium, provided the original author(s) and source are credited.

\section{References}

1. Voitsekhovskii, B.V., Mitrofanov, V.V., Topchiyan, M.E.: Structure of the detonation front in gases. In: Izdatielstvo SOAN SSSR, Novosibirsk (1963) (in Russian)

2. Voitsekhovskii, B.V.: Stationary detonation. Dokl. Akad. Nauk SSSR 129(6), 1254-1256 (1959)
3. Tobita, A., Fujiwara, T., Wolanski, P.: Detonation engine and flying object provided therewith. Japanese Patent No. 2004-191793 (granted 2009), US Patent No. US 7,784,267 B2 (granted Aug. 31, 2010)

4. Bykovskii, F.A., Zhdan, S.A., Vedernikov, E.F.: Continuous spin detonation of hydrogen-oxygen mixtures. 1. Annular cylindrical combustors. Combust. Explos. Shock Waves 44(2), 150-162 (2008)

5. Bykovskii, F.A., Vedernikov, E.F.: Continuous detonation of a subsonic flow of a propellant. Combust. Explos. Shock Waves 39(3), 323-334 (2003)

6. Bykovskii, F.A., Zhdan, S.A., Vedernikov, E.F.: Continuous spin detonation in annular combustors. Combust. Explos. Shock Waves 41(4), 449-459 (2005)

7. Yi, T.-H., Turangan, C., Liu, T., Wolanski, P., Kindracki, J.: Spinning detonation wave in an annular chamber. In: Proceedings of 20th International Symposium on Combustion Processes, Pultusk, Poland (2007)

8. Wolanski, P., Kindracki, J., Fujiwara, T.: An experimental study of small rotating detonation engine. In: Roy, G., Frolov, S., Sinibaldi, J. (eds.) Pulsed and Continuous Detonations, pp. 332-338. Torus Press, Moscow (2006)

9. Kailasanath, K.: Review of propulsion applications of detonation waves. AIAA J. 38(9), 1698-1708 (2000)

10. Chao, T.W., Wintenberger, E., Shepherd, J.E.: On the design of pulse detonation engines. GALCIT Report FM 00-7 (2001)

11. Kindracki, J.: Badania eksperymentalne i symulacje numeryczne procesu wirującej detonacji gazowej. Ph.D. Thesis (2008)

12. Kobiera, A., Folusiak, M., Swiderski, K., Kindracki, J., Wolanski, P.: Three-dimensional modeling of the rotating detonation engine. In: Proceedings of 22nd ICDERS, 27-31 July, Minsk, Belarus (2009)

13. Hishida, M., Fujiwara, T., Wolanski, P.: Fundamentals of rotating detonation. Shock Waves 19, 1-10 (2009)

14. McBride, B.J., Gordon, S.: Computer Program for Calculation of Complex Chemical Equilibrium Compositions and Applications. II. User Manual and Program Description. NASA Reference Publication 1311 (1994)

15. Gordon, S., McBride, B.J.: Computer Program for Calculation of Complex Chemical Equilibrium Compositions and Applications. I. Analysis, NASA Reference Publication 1311 (1994). http://www. grc.nasa.gov/WWW/CEAWeb/ceaHome.htm 